\title{
In vivo commitment to yeast cotranscriptional splicing is sensitive to transcription elongation mutants
}

\author{
Scott A. Lacadie, Daniel F. Tardiff, Sebastian Kadener, and Michael Rosbash ${ }^{1}$ \\ Howard Hughes Medical Institute, Biology Department, Brandeis University, Waltham, Massachusetts 02454, USA
}

\begin{abstract}
Spliceosome assembly in the budding yeast Saccharomyces cerevisiae was recently shown to occur at the site of transcription. However, evidence for cotranscriptional splicing as well as for coupling between transcription and splicing is still lacking. Using modifications of a previously published chromatin immunoprecipitation (ChIP) assay, we show that cotranscriptional splicing occurs $\sim 1 \mathrm{~kb}$ after transcription of the $3^{\prime}$ splice site (3'SS). This pathway furthermore protects most intron-containing nascent transcripts from the effects of cleavage by an intronic hammerhead ribozyme. This suggests that a high percentage of introns are recognized cotranscriptionally. This observation led us to screen a small deletion library for strains that sensitize a splicing reporter to ribozyme cleavage. Characterization of the $\Delta m u d 2$ strain indicates that the early splicing factor Mud2p functions with U1 snRNP to form a cross-intron bridging complex on nascent pre-mRNA. The complex helps protect the transcript from ribozyme-mediated destruction and suggests an intron-definition event early in the spliceosome assembly process. The transcription elongation mutant strains $\Delta d s t 1$ and $\Delta$ paf1 show different cotranscriptional splicing phenotypes, suggesting that different transcription pathways differentially impact the efficiency of nascent intron definition.
\end{abstract}

[Keywords: Splicing; transcription; ribozyme; TFIIS; Paf1; Mud2]

Supplemental material is available at http://www.genesdev.org.

Received March 28, 2006; revised version accepted June 1, 2006.

Nuclear pre-mRNA processing consists of three covalent steps: capping of the $5^{\prime}$ end with a 7-methyl-guanosine nucleotide, $3^{\prime}$ end formation and polyadenylation, and splicing. Capping and 3' end formation are cotranscriptional, and there is good evidence that splicing is also cotranscriptional in many cases (for review, see Bentley 2005). These processes are accompanied and often preceded by the noncovalent recruitment of factors important for these steps as well as nascent RNP assembly more generally. The C-terminal domain of RNA polymerase II (PolII CTD) has been shown to play an important role in coupling transcription and pre-mRNA processing. It consists of a heptad consensus sequence, YSPTSPS, which is repeated 52 times in higher eukaryotes and 26 times in yeast, as well as dynamically phosphorylated at serines 2 and 5 throughout the transcription cycle. Serine 5 phosphorylated CTD is enriched at the 5 ' end of genes and contributes to capping machinery recruitment (Cho et al. 1997, 1998; McCracken et al. 1997a; Rodriguez et al. 2000). Serine 2 phosphorylated CTD is enriched throughout coding regions and helps recruit a variety of complexes, including the $3^{\prime}$ end formation machinery (Hirose and Manley 1997; Ahn et al.

${ }^{1}$ Corresponding author.

E-MAIL rosbash@brandeis.edu; FAX (781) 736-3164.

Article is online at http://www.genesdev.org/cgi/doi/10.1101/gad.1434706.
2004). All of these interactions are conserved from yeast to humans.

Splicing and transcription are also related in metazoans; i.e., the PolII CTD has also been shown to physically interact with splicing factors (Mortillaro et al. 1996; Vincent et al. 1996; Yuryev et al. 1996; Du and Warren 1997; Kim et al. 1997) and positively influence the splicing reaction, both in vivo and in vitro (McCracken et al. 1997b; Hirose et al. 1999). Splicing factors concentrate within dynamic nuclear bodies called speckles (Spector 1993) and are recruited to genes upon transcription activation (Misteli et al. 1997), presumably through interactions with PolII CTD (Misteli and Spector 1999). A reverse relationship has also been reported; namely, the presence of a promoter proximal intron has been shown to increase the amount of nascent transcription (Furger et al. 2002). Moreover, the targeting of splicing factors to a gene resulted in the stimulation of transcription elongation via the TAT-SF1 transcription elongation factor (Fong and Zhou 2001). Taken together, all of these observations suggest a reciprocal relationship between transcription and splicing: PolII helps recruit splicing factors to nascent introns, which in turn encourage further transcription (Rosonina and Blencowe 2002). Finally, alternative splicing can be influenced by transcription from different promoters and/or by faster or slower 
polymerases (Kadener et al. 2002; de la Mata et al. 2003). Although many of these data only indicate interactions between the transcription machinery and splicing factors, splicing itself can also be cotranscriptional /Osheim et al. 1985; Beyer and Osheim 1988; LeMaire and Thummel 1990; Bauren and Wieslander 1994; Wuarin and Schibler 1994; Dye and Proudfoot 1999; Wetterberg et al. 2001).

In contrast to metazoa, little direct evidence links splicing and transcription in yeast (Saccharomyces cerevisiae). Two splicing factors have been shown to associate with PolII: the U1 snRNP protein Prp40p and the splicing/export factor Sub2p (Morris and Greenleaf 2000; Libri et al. 2001; Strasser and Hurt 2001; Strasser et al. 2002). Introns and splicing factors have also been shown to inhibit the cotranscriptional recruitment of mRNA export factors, suggesting a competition between intron recognition by the spliceosome and the nascent deposition of export-relevant RNP proteins (Lei et al. 2001; Lei and Silver 2002; Abruzzi et al. 2004). It was more recently shown that spliceosome assembly occurs cotranscriptionally and probably follows the traditional stepwise pathway of snRNP association long indicated by in vitro splicing assays (Kotovic et al. 2003; Gornemann et al. 2005; Lacadie and Rosbash 2005). All of these data suggest that yeast splicing itself might occur on nascent transcripts and that there might also be functional connections between splicing and transcription in this model system.

In this manuscript, we introduce two novel assays to demonstrate and then study yeast cotranscriptional splicing. The first shows that cotranscriptional cleavage of an intronic ribozyme (RZ) is efficiently bypassed by the splicing pathway. The second shows directly that yeast splicing occurs cotranscriptionally and is easily detectable when polymerases are $\sim 1 \mathrm{~kb}$ past the position that encodes the $3^{\prime}$ SS. A plate assay based on competition between RZ cleavage and cotranscriptional splicing events facilitated a small pilot screen, which identified mutant strains that influence cotranscriptional splicing efficiency. Characterization of three strains suggests that commitment to the cotranscriptional splicing pathway can be influenced by transcription as well as by spliceosome assembly. Moreover, deletions of two different transcription elongation factors impact splicing in different ways, indicating that these assays access the interface between transcription and cotranscriptional splicing in yeast.

\section{Results}

\section{Effects of an intronic hammerhead ribozyme}

To address the control of cotranscriptional spliceosome assembly and splicing, we established a competitive situation between splicing and the cleavage activity of a hammerhead ribozyme sequence situated in the middle of an intron. The ribozyme was inserted midway between the $5^{\prime}$ splice site $\left(5^{\prime} \mathrm{SS}\right)$ and branchpoint (BP) regions of the RP51A intron within the high copy plasmid
lacZ reporter gene $H Z 18$ (Teem and Rosbash 1983); a control point mutant ribozyme sequence was inserted in parallel (RZ, mutRZ) (Fig. 1A; Samarsky et al. 1999). These same two insertions were also made within an $H Z 18$ variant missing its 5'SS ( $\left.\Delta 5^{\prime} \mathrm{SS}\right)$ (Fig. 1A; Lacadie and Rosbash 2005). To assay cotranscriptional cleavage by the RZ sequence, we used our previously described chromatin immunoprecipitation (ChIP) assay for the phage RNA binding coat protein MS2 (Abruzzi et al. 2004) and inserted a single MS2 stem-loop within the 5' exon of the four RZ-mutRZ (GTATGT or $\Delta 5^{\prime}$ SS) splicing reporters (Fig. 1A). The high copy reporter genes were each transformed into yeast along with a plasmid expressing HA-tagged MS2, and anti-HA ChIPs were followed by quantitative real-time PCR of the lacZ open reading frame.

To ask if the ribozyme could cut cotranscriptionally, the two reporters containing the 5'SS deletion (Fig. 1A, $\Delta 5^{\prime}$ SS) were assayed by ChIP, and the data are presented as a ratio of IP to input relative to the first primer pair, i.e., the first data point just after the intron (Fig. 1B, Y axis). Both genes failed to splice (Lacadie and Rosbash 2005) and had interesting ChIP profile differences: The mutRZ showed significant signal approximately fivefold over background, which was apparent at $\sim 100$ bp past the intron and remained high for an additional $2 \mathrm{~kb}$ (Fig. 1B, red; note that in all graphs the $X$-axis is plotted as distance from the start codon and not distance from the intron). In contrast, the RZ signal progressively declined and approached background levels near the end of the lacZ gene (Fig. 1B, blue). The data indicate that the intronic ribozyme efficiently cleaves cotranscriptionally as previously suggested (Fig. 1B, right; Huertas and Aguilera 2003; West et al. 2004). In the case of the wild-type intron (Fig. 1C), however, the signal from the active RZ containing reporter showed little difference from its inactive mutRZ counterpart (Fig. 1C, cf. red and blue). This is because the RZ sequence has little effect on the ChIP signal in a wild-type intron context /cf. blue in Fig. 1C and $1 \mathrm{~B})$. These comparisons indicate that the splicing pathway is efficiently inhibiting or bypassing cotranscriptional ribozyme cleavage activity (Fig. 1C, right).

\section{Splicing occurs cotranscriptionally in yeast $\sim 1 \mathrm{~kb}$ after the 3'SS}

The RZ cleavage assay suggests that a large fraction of nascent introns are spliced cotranscriptionally before RZ cleavage takes place. Alternatively, it is possible that only a fraction of the spliceosome assembly pathway is necessary to inhibit or bypass effective RZ cleavage. To address the possibility of cotranscriptional splicing in yeast, we again resorted to MS2 ChIP assays. In one reporter system, a single MS2 stem-loop was placed halfway between the 5'SS and BP of $H Z 18$, with and without a functional 5'SS (GTATGT, $\Delta 5^{\prime}$ SS) (Fig. 2A, top). These two intron MS2 reporters were each transformed into yeast along with the HA-MS2 plasmid, and anti-HA ChIPs were performed followed by quantitative realtime PCR. 


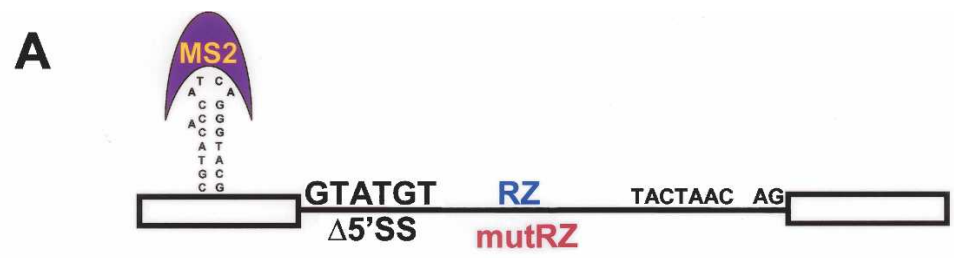

B
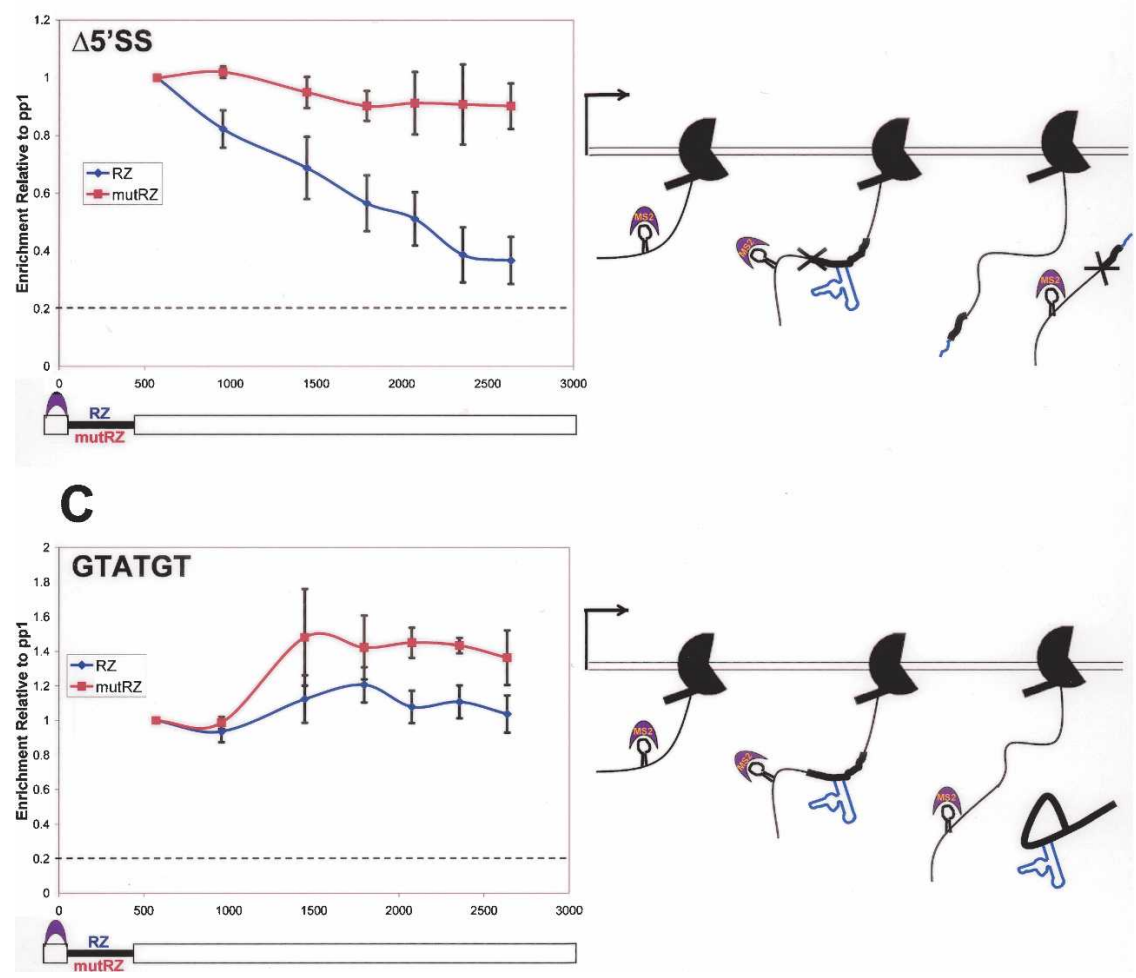

The wild-type intron MS2 reporter showed significant ChIP signal $\sim 100$ bp past the intron (intron MS2) (Fig. 2B, blue), similar to that seen for the 5' Exon MS2 (Fig. 1). The intron MS2 signal then gradually decreased to background levels by $\sim 2 \mathrm{~kb}$ past the intron (Fig. $2 \mathrm{~B}$ ). The data suggest that a fraction of intron removal has occurred by $\sim 500$ bp and that most or all nascent introns have been spliced out by transcription $1.5 \mathrm{~kb}$ past the intron sequence. In contrast, the intron MS2 $\Delta 5^{\prime}$ SS reporter maintained a high signal within the same gene regions (intron MS2 $\Delta 5^{\prime}$ SS) (Fig. 2B, red), consistent with the notion that splicing is responsible for removal of the MS2 sequence from the nascent chromatin.

In a second splicing-reporter system, the single MS2 binding sequence (with two extra bases to maintain the open reading frame [ORF]) was divided between the $5^{\prime}$ and 3 ' exons so that only splicing could reconstitute the intact stem-loop (split MS2) (Fig. 2A). HA-MS2 ChIPs for this reporter showed the opposite pattern to the intron stem-loop: Signals just after the intron were comparable to background and increased down the gene (split MS2) (Fig. 2C, blue). Significant split MS2 signal was first detected $\sim 1 \mathrm{~kb}$ past the intron and peaked by $1.5 \mathrm{~kb}$ (Fig. 2C). In contrast, the same split MS2 sequences inserted
Figure 1. Cleavage activity of an intronic ribozyme occurs cotranscriptionally and is averted by the splicing pathway. (A) Four splicing reporter plasmids containing a single $5^{\prime}$ exon MS2 stem-loop were derived from the galactose-driven RP51alacZ fusion gene HZ18 (Teem and Rosbash 1983) with and without a 5'SS (GTATGT, $\Delta 5^{\prime}$ SS) and with either an active ribozyme (RZ [blue]) or a point mutation killing the RZ activity (mutRZ [red]). HA-MS2 ChIPs were performed as described (see Materials and Methods) on the wild-type reporter genes (GTATGT) with (RZ [blue]) and without (mutRZ [red]) an active ribozyme. The $Y$-axis represents fold enrichment relative to the first primer pair. The gene model shows the location of the MS2 site (purple), the intron (black line), the RZ sequences, and the lacZ coding sequence (rectangle), and is drawn to scale with the $X$-axis, which represents the distance from the start codon. The dashed line within the graph shows the level of background MS2 signal as measured by the amount of DNA bound from the PMA1 gene relative to the first primer pair. (B) MS2 ChIPs for the reporters lacking a $5^{\prime} \mathrm{SS}\left(\Delta 5^{\prime} \mathrm{SS}\right)$ with the active RZ (RZ [blue]) or inactive RZ (mutRZ [red]) show that RZ cutting occurs cotranscriptionally when splicing is abrogated. $(C)$ The patterns of the RZ and mutRZ curves are very similar, suggesting that little cleavage activity is occurring before splicing. The schemes to the right of each graph display a pictorial interpretation of the data. into a $\Delta 5^{\prime}$ SS gene maintained background binding, indicating that splicing is indeed necessary to constitute the MS2 sequence (split MS2 $\Delta 5^{\prime}$ SS) (Fig. 2C, red). A superposition of the split MS2 ChIP curve with ChIP curves for the cotranscriptional recruitment of U1, U2, and U5 snRNPs performed as published previously (Lacadie and Rosbash 2005) indicates that significant splicing increases in parallel with U2 and U5 recruitment and dissociation (Fig. 2D). We conclude that cotranscriptional spliceosome assembly and/or splicing protects the nascent transcript from RZ cleavage and destruction.

\section{Deletion of the MUD2 gene sensitizes an intron to cotranscriptional ribozyme cleavage}

We then exploited these assays to establish a screen for factors that altered the balance between splicing/spliceosome assembly on the one hand and RZ cleavage on the other. To this end, we also made use of the third feature of these reporters, namely, the splicing-dependent synthesis of lacZ. $\beta$-Galactosidase levels should be (and are; see below) similar between an intronic RZ-containing HZ18 reporter and its mutRZ counterpart. However, a mutation that delays the timing of splicing or spliceo- 
Lacadie et al.
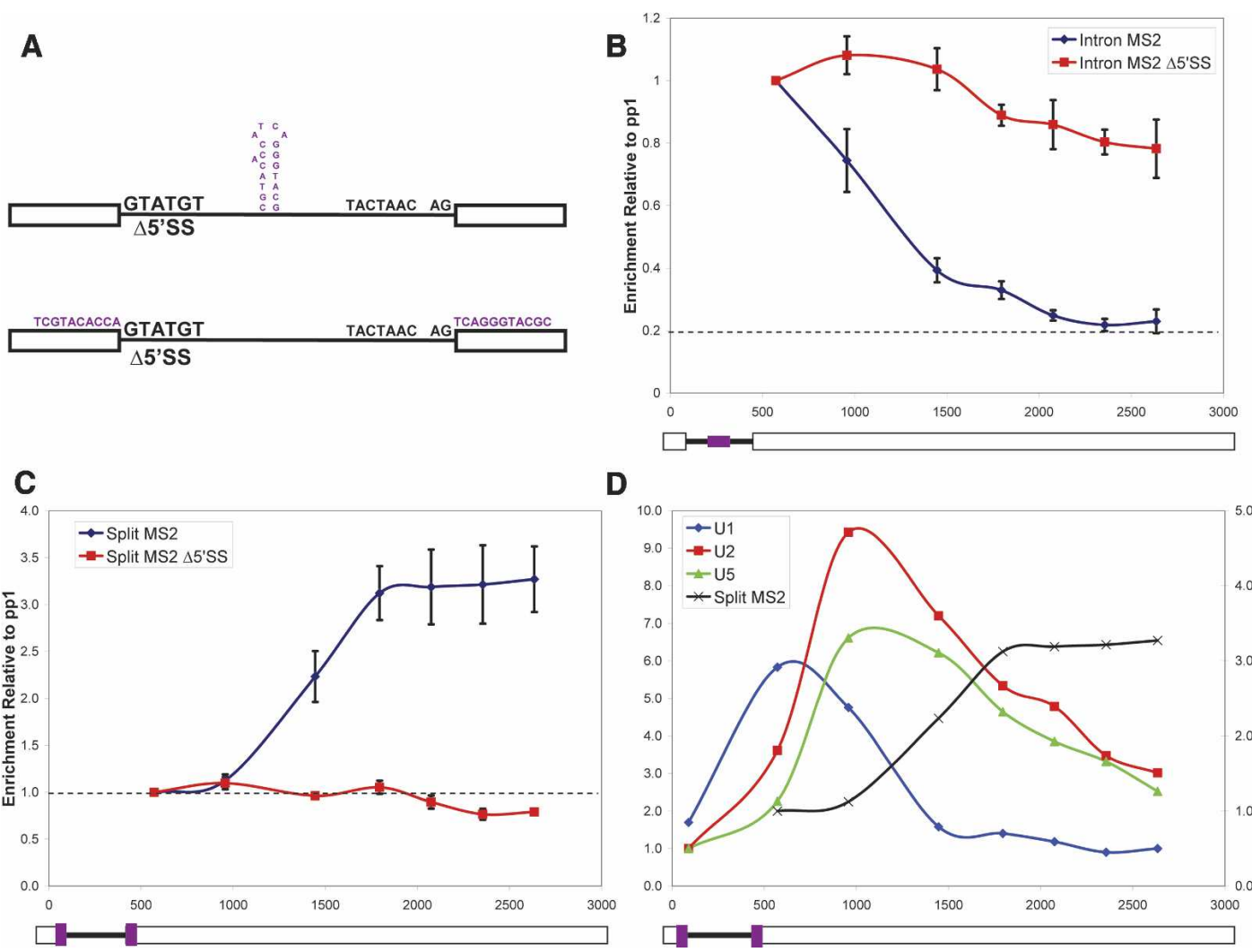

D

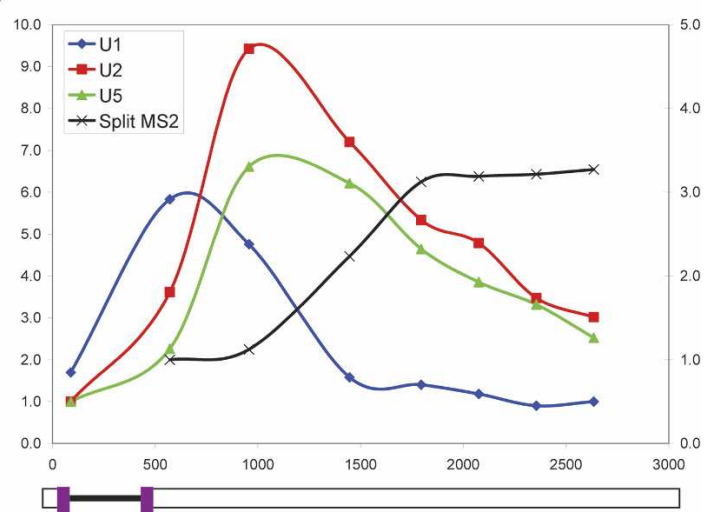

Figure 2. MS2 ChIPs to intronic MS2 or split MS2 reporters show that splicing occurs cotranscriptionally $\sim 1 \mathrm{~kb}$ past the 3'SS. (A) Derivatives of the HZ18 gene were constructed to incorporate a single MS2 stem-loop (purple) within the intron (top) or split between exons one and two (bottom). Aside from the wild-type intron (GTATGT) each reporter was also made with a corresponding deletion of the $5^{\prime}$ splice site $\left(\Delta 5^{\prime} S S\right)$ to kill splicing (Lacadie and Rosbash 2005). HA-MS2 ChIPs were performed as described (see Materials and Methods), and the graphs are presented as described in the legend to Figure 1. (B) MS2 ChIPs to the intron MS2 (blue) and intron MS2 $\Delta 5^{\prime} \mathrm{SS}$ (red) reporters showed that the intron is removed cotranscriptionally dependent upon a wild-type 5'SS. (C) MS2 ChIPs to the split MS2 (blue) and split MS2 $\Delta 5^{\prime}$ SS (red) show that exon ligation occurs cotranscriptionally dependent upon a wild-type 5'SS. (D) ChIPs for U1, U2, and U5 snRNPs were performed as described (see Materials and Methods) to the split MS2 reporter and overlaid with the MS2 ChIP data from C. U1 snRNP recruitment (blue) peaks before U2 (red) and U5 (green). The dissociation of U2 and U5 correlate with the appearance of split MS2 signal (black).

some assembly might cause a reduction in RZ lacZ activity compared to the mutRZ lacZ activity, all of which can be assayed on plates. We also combined the RZ / and mutRZ) insertion with the split MS2 exons to provide a biochemical subscreen, i.e., a split MS2 RZ versus mutRZ ChIP assay in candidate mutant backgrounds. In fact, this pair of split MS2 HZ18 (RZ vs. mutRZ) reporters was used for the initial plate screen. A group of $\sim 75$ viable deletion mutants from the yeast knockout library (Open Biosystems) (Winzeler et al. 1999) with proposed functions in mRNA export, mRNP formation, premRNA processing, transcription initiation, transcription elongation, and chromatin remodeling was assayed (see Materials and Methods for a list of tested mutants). Each strain was transformed with each of the two reporters and with the plasmid expressing HA-MS2, plated on XGal-containing media with galactose to induce HZ18 expression, and analyzed after 2-3 d of growth for blue color intensity as a readout of $\beta$-galactosidase activity.

In a wild-type background the $\beta$-galactosidase activity is marginally less for the split MS2 RZ reporter com- pared to the split MS2 mutRZ reporter (Fig. 3A, top panels). This observation is consistent with the RZ ChIP assay (Fig. 1) and suggests that a high percentage of nascent introns are able to bypass or inhibit RZ cleavage. We noticed that a deletion of the splicing factor Mud2p gave a robust intensity difference between RZ and mutRZ signals (Fig. 3A, bottom panels). The mutRZ construct is noticeably less active in the $\Delta$ mud2 background than in a wild-type strain, suggesting that even splicing of the mutRZ-containing intron is dependent on the presence of Mud2p (see Discussion). Much more impressive, however, was the RZ reporter difference between the two strains, as it was almost completely white in the $\Delta$ mud2 background, suggesting that a lack of Mud2p sensitizes the intron to RZ cleavage activity (Fig. 3A, bottom panels). Similar observations were made with liquid $\beta$-galactosidase assays, which showed reduced expression of both reporter genes as well as increased RZ cleavage in the $\Delta$ mud2 background: RZ cleavage was $\sim 55 \%$ in wild-type and $\sim 75 \%$ in $\Delta$ mud2 (data not shown; see Discussion). 
A
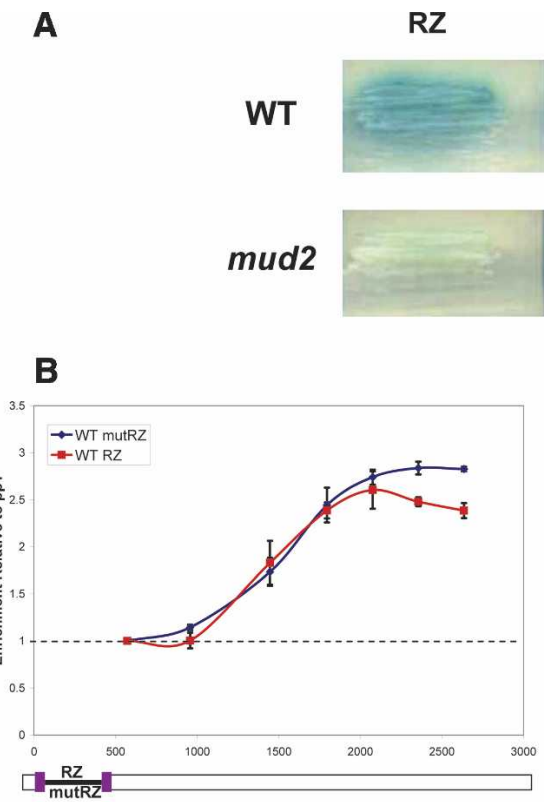

D

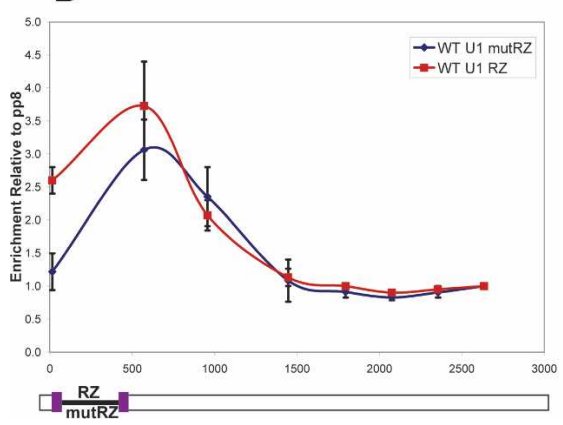

mutRZ

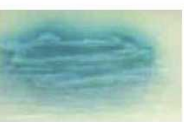

C

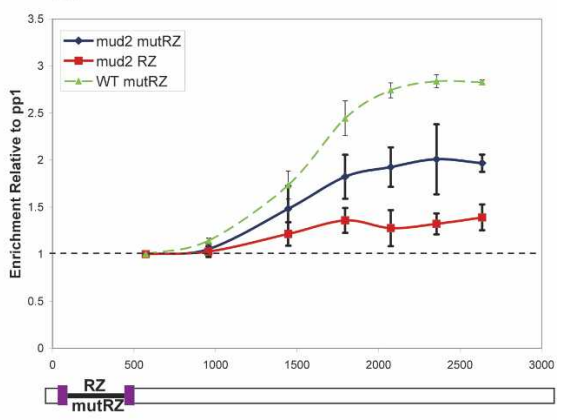

E

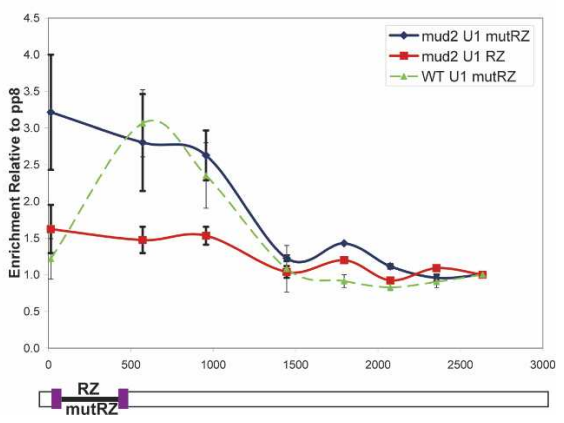

Figure 3. Deletion of $M U D 2$ sensitizes an intron to RZ cleavage. (A) Split MS2 derivatives of $H Z 18$ with the RZ or mutRZ were transformed into wild-type (top panels) or $\Delta$ mud2 (bottom panels) strains and assayed for $\beta$-gal activity as described (see Materials and Methods). $\Delta$ mud2 increases the difference in blue intensity between the RZ and mutRZ reporters (bottom panels) compared to wildtype (top panels). $(B, C)$ HA-MS2 ChIPs were performed as described (see Materials and Methods), and the data are presented as described in the legend to Figure 1. $(B)$ MS2 ChIPs for the split MS2 mutRZ (blue) and RZ (red) reporters show little to no difference in a wild-type background. $(C)$ In the $\Delta$ mud2 background the split MS2 mutRZ (blue) signal is reduced compared to the same experiment in the wild-type strain (green), and the $\Delta$ mud2 split MS2 RZ (red) signal is even further reduced. $(D, E)$ U1 snRNP ChIPs were performed as described (see Materials and Methods), and the data are presented as described in the legend to Figure 1, except that the $Y$-axis represents the enrichment of DNA relative to the background signal seen at the last primer pair. $(D)$ In a wild-type strain, U1 snRNP recruitment to the split MS2 $\mathrm{RZ}$ (red) is very similar to that for the split MS2 mutRZ (blue) aside from a modest increase at the first primer pair. (E) U1 snRNP recruitment in the $\Delta$ mud2 strain is altered for both the split MS2 mutRZ (blue) as well as the split MS2 RZ (red) compared to the wild-type split MS2 mutRZ (green), and there is indeed a RZdependent reduction (compare red to blue).
To confirm this observation, we assayed these split MS2 reporters by ChIP in the wild-type and $\Delta$ mud2 backgrounds. As suspected, very little difference in cotranscriptional splicing was observed in the wild-type strain, indicating that these nascent transcripts splice cotranscriptionally and are resistant to RZ-cleavage (Fig. 3B). As shown previously (Fig. 2C), the split MS2 RZ and mutRZ genes manifest background levels just after the intron, which increase significantly by $1 \mathrm{~kb}$ past the intron and peak by $\sim 1.5 \mathrm{~kb}$ (Fig. $3 \mathrm{~B}$ ). In contrast, the $\Delta$ mud2 background showed reduced split MS2 mutRZ ChIP signal, which was reduced even further with the active RZ. These differences between RZ and mutRZ could not be attributed to differences in levels of RNA PolII as assayed by ChIP with the 8WG16 antibody (Supplementary Fig. 1A,B). These split MS2 ChIP data agree well with the observed plate phenotypes, suggesting that the absence of Mud2p affects cotranscriptional splicing efficiency in a manner that sensitizes the intron to RZ cleavage activity (see Discussion).

Because Mud2p binds to the intronic branchpoint region and impacts in vitro spliceosome assembly at the level of commitment complex formation (U1 snRNP complex formation) (Abovich et al. 1994; Rain and Legrain 1997; Rutz and Seraphin 1999|, we suspected that the RZ phenotypes might also be evident at the level of cotranscriptional U1 snRNP recruitment. To address this possibility, we exploited the U1 snRNP ChIP assay (Kotovic et al. 2003; Gornemann et al. 2005; Lacadie and Rosbash 2005) and transformed the split MS2 reporters into a yeast strain with a TAP tag on the U1 snRNP protein U1C (Lacadie and Rosbash 2005). This was done either in a wild-type or a $\Delta$ mud2 strain background, and ChIPs with IgG-sepharose were performed as described (Lacadie and Rosbash 2005); the data are presented as a ratio of IP to input relative to the last primer pair.

With the exception of the beginning of the curves, the U1 snRNP patterns in a wild-type strain background are virtually indistinguishable between both reporter genes and similar to what had been previously reported for the wild-type HZ18 gene (Fig. 3D; Lacadie and Rosbash 2005). In contrast, the U1 patterns in the $\Delta$ mud2 background were flatter and had their peaks shifted from the second to the first primer pair for both the mutRZ and 
Lacadie et al.

RZ reporters (Fig. 3E). Importantly, U1 snRNP levels were also significantly reduced for the active RZ compared to the mutRZ in this background (Fig. 3E, cf. red and blue). This explains the reduced $\beta$-gal and split MS2 signals for RZ relative to mutRZ and implicates Mud2p in a cross-intron bridging role during cotranscriptional commitment complex formation in vivo, as predicted from in vitro experiments (Abovich and Rosbash 1997; Berglund et al. 1997, 1998).

We recently reported that branchpoint mutations influence U1 recruitment; moreover, robust U1 recruitment was still observed on an intron with no 5'SS (Lacadie and Rosbash 2005). Taken together with the observations shown above, we suspected that Mud2p was particularly important for recruiting U1 to the branchpoint region in the absence of wild-type 5'SS activity. To test this hypothesis, we used the original HZ18 reporter and two variants with a weakened 5'SS for U1 ChIP assays: The 5'II construct contains a GUAUaU instead of the wild-type GUAUGU, resulting in $50 \%$ of wild-type protein expression, and the $\Delta 5^{\prime} S S$ construct cannot splice and therefore has no $\beta$-galactosidase activity (Fig. 4A; Jacquier et al. 1985; Lacadie and Rosbash 2005). The two 5'SS mutant reporters along with the wild-type gene were transformed into TAP-tagged U1C strains, either in a wild-type background or in $\Delta$ mud2.

The $\Delta$ mud2 strain has no detectable effect on U1 recruitment to a wild-type intron (cf. Fig. 4B; see Discussion). When the 5'SS is compromised by the 5'II mutation, however, U1 levels are significantly reduced in the $\Delta$ mud2 background (Fig. 4C, solid vs. dashed). This effect is more extreme than that of the $5^{\prime}$ II mutation alone, which shifts the signal of U1 recruitment by $500 \mathrm{bp}$ downstream as previously shown (cf. Fig. 4C and 4B; Lacadie and Rosbash 2005). When the 5'SS is further impaired by the $\Delta 5^{\prime}$ SS mutation, peak U1 levels are even more reduced than by the $5^{\prime}$ II mutation (cf. solid and dashed in Fig. 4C,D). The data indicate that the branchpoint region interaction with U1 snRNP is strongly dependent on Mud2p, which explains the sensitivity of U1 recruitment to an intronic $\mathrm{RZ}$ element in the $\Delta$ mud2 background (see Discussion).
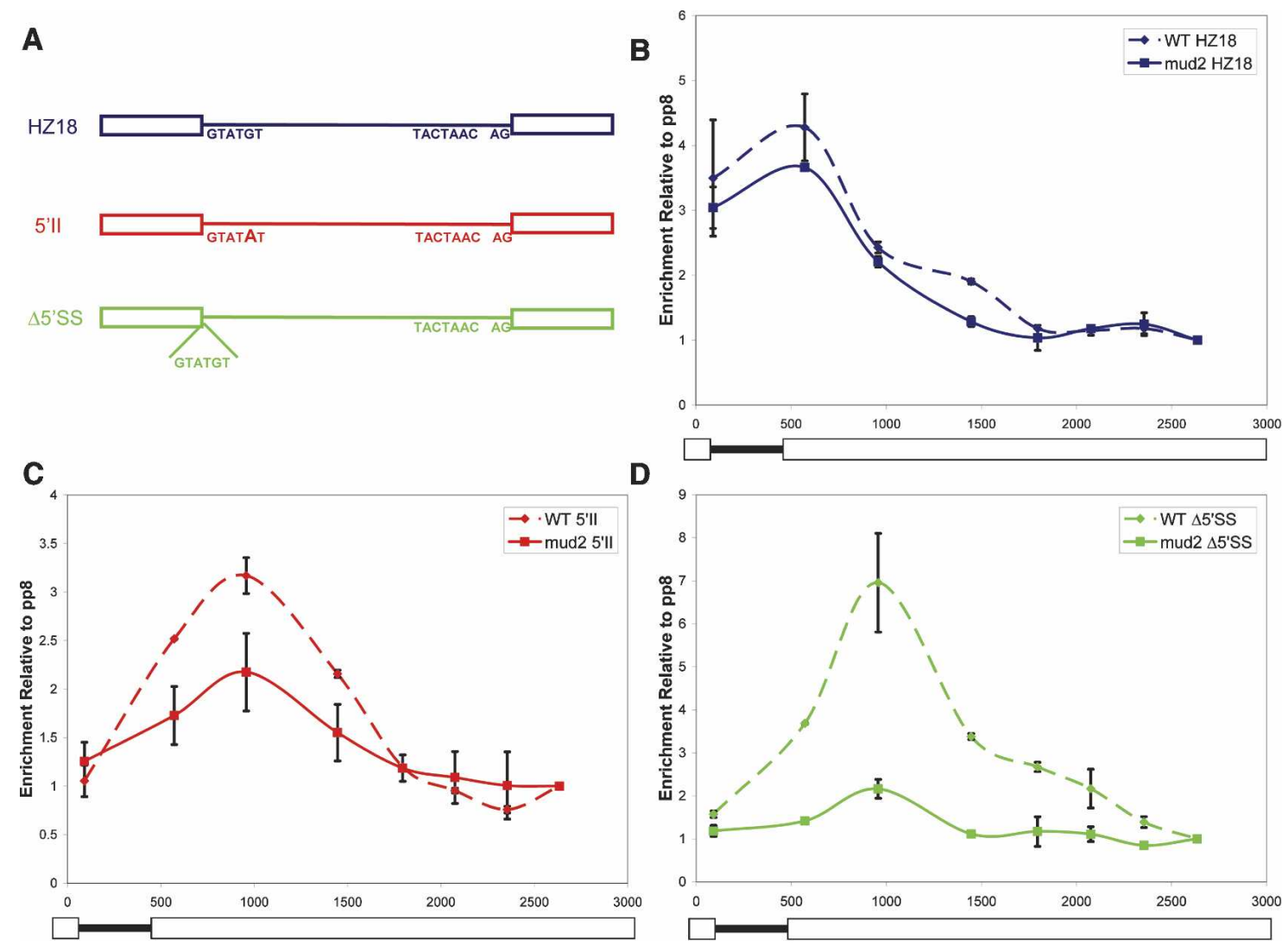

D

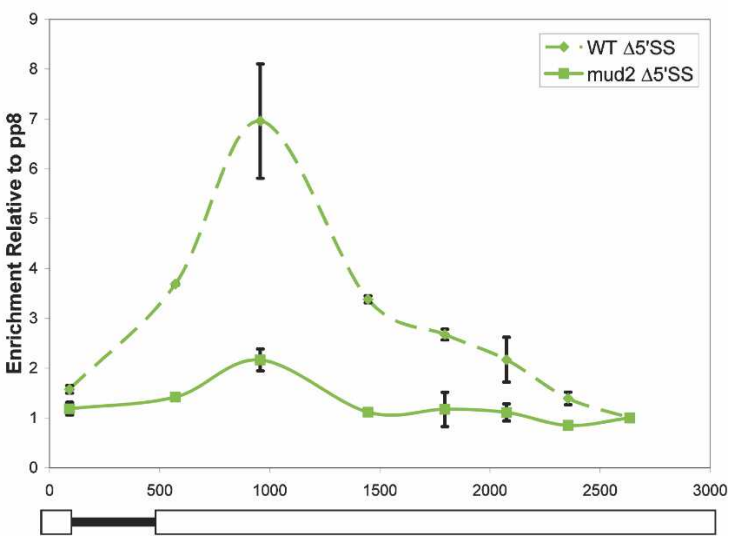

Figure 4. Mud2p facilitates U1 snRNP recruitment to introns with compromised 5 ' splice sites. (A) HZ18 (blue) and two derivatives containing weak (5'II [red]) or strong $\left(\Delta 5^{\prime}\right.$ SS [green]) $5^{\prime}$ splice site mutations were transformed into wild-type or $\Delta$ mud2 yeast tagged for the U1 snRNP protein U1C (Lacadie and Rosbash 2005). (B-D) U1 snRNP ChIPs were performed as described (see Materials and Methods), and the data are presented as described in the legend to Figure 3. (B) U1 snRNP recruitment to HZ18 in the $\Delta$ mud2 background (solid line) is very similar to that seen in the wild-type background (dashed line) (Lacadie and Rosbash 2005). (C) The shifted U1 snRNP recruitment observed to the 5'II reporter (dashed line) (Lacadie and Rosbash 2005) is significantly reduced in the $\Delta$ mud2 strain (solid line). (D) The shifted and elevated U1 snRNP recruitment observed for the $\Delta 5^{\prime}$ SS reporter (dashed) (Lacadie and Rosbash 2005) is even more significantly reduced by the Mud2p deletion (solid line). 
Deletion of TFIIS sensitizes an intron to cotranscriptional ribozyme cleavage

Another strain that gave strong RZ versus mutRZ plate and liquid (65\% cutting; see Discussion) phenotypes was $\Delta d s t 1$ (Fig. 5A); DST1 encodes the transcription elongation factor TFIIS. The splitMS2 RZ versus mutRZ ChIP assay in the $\Delta d s t 1$ background confirmed that the plate lacZ results largely reflects cotranscriptional splicing events (Fig. 5B). Moreover, the results were similar to those shown above for the $\Delta$ mud2 strain, except that the effect of $\Delta d s t 1$ on mutRZ splicing was negligible-also consistent with the plate results (Fig. 5A). The difference between the RZ and mutRZ in the $\Delta d s t 1$ background was not due to changes in RNA PolII levels (Supplementary Fig. 1C). We then assayed cotranscriptional U1 snRNP recruitment to the RZ and mutRZ genes in the $\Delta d s t 1$ background. Surprisingly, and unlike the results shown above for the $\Delta$ mud2 strain (Fig. 3E), there was no decreased U1 snRNP recruitment in the $\Delta d s t 1$ strain (Fig. 5C), suggesting that the RZ sensitivity to splicing may occur at a later stage of spliceosome assembly (see Discussion).

\section{Deletion of Paf1p does not confer ribozyme sensitivity}

Because of the strong TFIIS effect, we examined another transcriptional elongation factor deletion strain with a lacZ plate phenotype, $\Delta p a f 1$. Paflp is a component of the polymerase-associated PAF complex, implicated in regulating transcription elongation as well as $3^{\prime}$ end formation (Rondon et al. 2004; Penheiter et al. 2005). In contrast to $\Delta$ mud2 and $\Delta d s t 1$, mutRZ and RZ plate phenotypes were comparably reduced in the $\Delta$ paf1 background (Fig. 6A). The split MS2 RZ/mutRZ ChIP assay confirmed the plate phenotype and showed no significant differences between the two reporters (Fig. 6B). Surprisingly, the levels of split MS2 ChIP signal were substantially higher in the $\Delta p a f 1$ strain (Fig. 6B). The increased signal is enigmatic and perhaps due to slower polymerase elongation (see Discussion). Indeed, PolII levels are somewhat higher with altered patterns in the mutant strain (see Discussion; Supplementary Fig. 1D). The $\Delta$ paf1 data indicate that a slow elongation phenotype is not sufficient to cause RZ sensitivity. Moreover, a comparison of the $\Delta p a f 1$ and the $\Delta d s t 1$ data (cf. Figs. 6 and 5) suggests that the two elongation proteins contribute differentially to cotranscriptional spliceosome assembly and splicing.

\section{Discussion}

Although substantial spliceosome assembly occurs cotranscriptionally in yeast (Gornemann et al. 2005; Lacadie and Rosbash 2005), there was no previous evidence for cotranscriptional splicing, i.e., RNA phosphodiester bond cleavage and formation. Using a modified version of a previously published ChIP assay for the phage RNA binding protein MS2 (Abruzzi et al. 2004), we describe here two novel assays for cotranscriptional

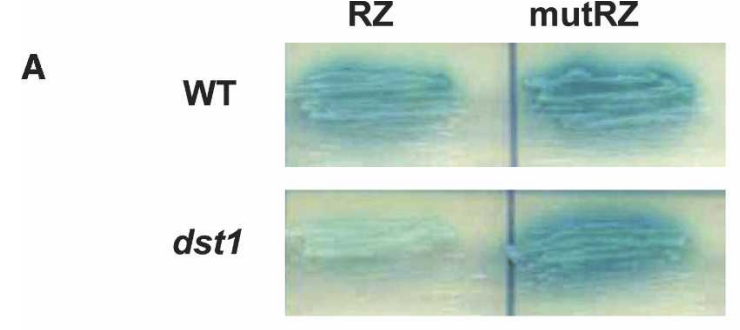

B

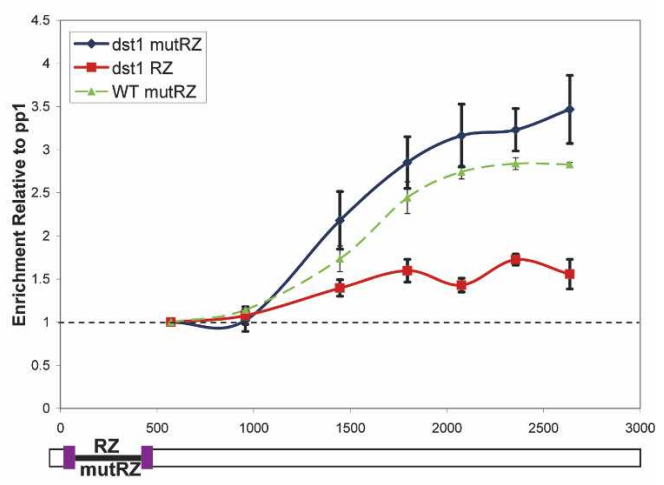

C

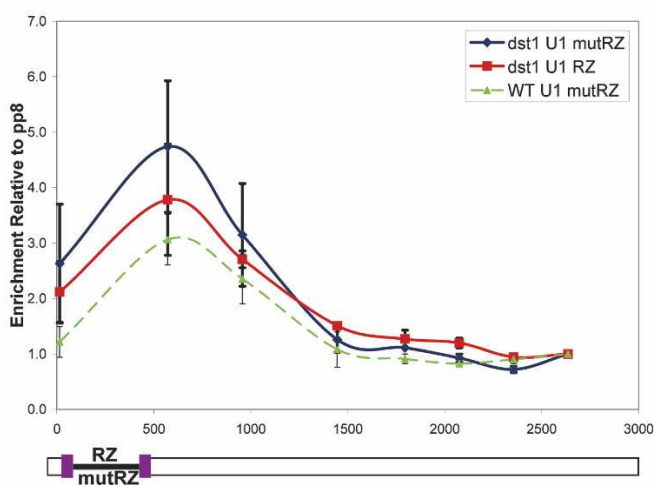

Figure 5. Deletion of DST1 (TFIIS) sensitizes an intron to ribozyme cleavage. (A) Split MS2 derivatives of $H Z 18$ with the RZ or mutRZ were transformed into wild-type (top panels) or $\Delta d s t 1$ (bottom panels) strains and were assayed for plate $\beta$-gal activity as described (see Materials and Methods). $\Delta d s t 1$ increases the difference in blue intensity between the RZ and mutRZ reporters (bottom panels) compared to wild-type (top panels). (B) HAMS2 ChIPs were performed as described (see Materials and Methods), and the data are presented as described in the legend to Figure 1 . MS2 ChIPs in the $\Delta d s t 1$ background show slightly elevated levels to the split MS2 mutRZ (blue) compared to the same experiment in a wild-type strain (green dashed line), and the signal is substantially reduced to the split MS2 RZ reporter (red). (C) U1 snRNP ChIPs were performed as described (see Materials and Methods), and the data are presented as described in the legend to Figure 3. U1 snRNP recruitment is relatively unaffected in the $\Delta d s t 1$ background to both the split MS2 mutRZ (blue) and split MS2 RZ (red) reporters, compared to signal seen to the split MS2 mutRZ reporter in a wild-type background (green dashed line).

splicing, which indeed occurs when polymerases are $\sim 1$ $\mathrm{kb}$ after transcription of the HZ18 3'SS. Moreover, the use of an intronic ribozyme sequence shows that the splicing pathway allows most pre-mRNAs to avoid the 
A

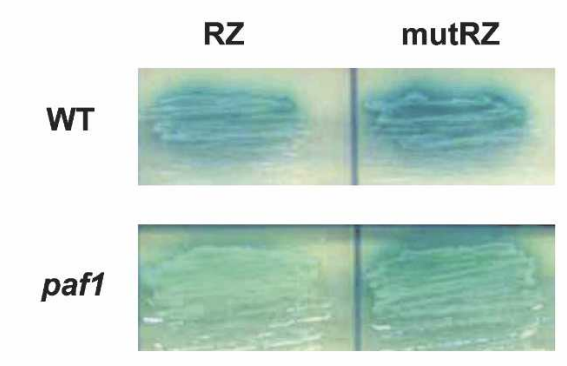

B

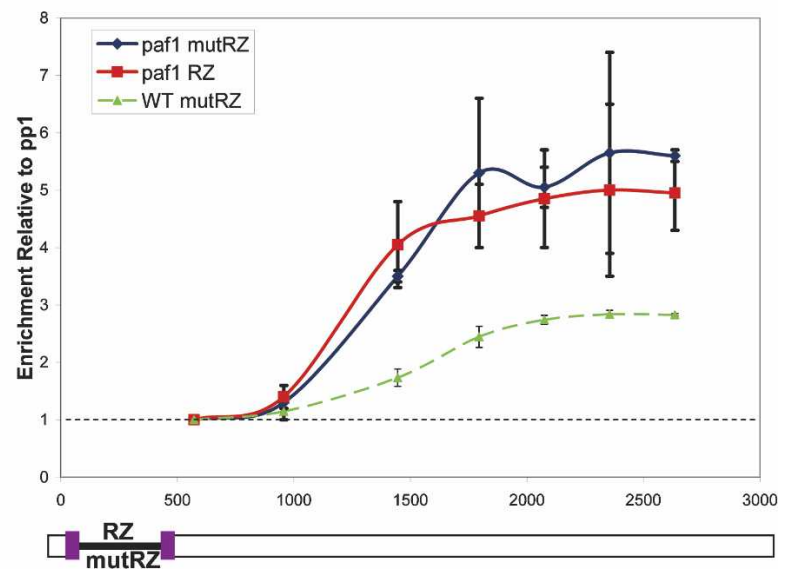

Figure 6. Deletion of the $P A F 1$ gene shows no RZ phenotypes. (A) Split MS2 derivatives of $H Z 18$ with the RZ or mutRZ were transformed into wild-type (top panels) or $\Delta$ paf1 (bottom panels) strains and were assayed for $\beta$-gal activity as described (see Materials and Methods). $\Delta p a f 1$ decreases the blue intensity for both the RZ and mutRZ reporters (bottom panels) maintaining the relative levels compared to wild-type (top panels). (B) HA-MS2 ChIPs were performed as described (see Materials and Methods), and the data are presented as described in the legend to Figure 1. The $\Delta$ paf1 strain shows increased MS2 levels for both the split MS2 mutRZ (blue) and split MS2 RZ (red) reporters compared to wild-type (green dashed line), and no significant difference between the two.

effects of cotranscriptional cleavage. This indicates that the ribozyme activity and the splicing pathway are in competition and lead to a small screen for mutants that sensitize this lacZ splicing reporter to intronic ribozyme cleavage.

Of the $\sim 75$ strains screened (see Materials and Methods for a list), only three gave robust plate RZ versus mutRZ phenotypes: two splicing factor gene deletions, $\Delta$ mud2 and $\Delta m s 11$, as well as a deletion of a transcription elongation factor, $\Delta d s t 1$. We chose to further characterize two of these strains along with a third strain, a deletion of the transcription elongation factor Paflp. $\Delta$ mud2 provides evidence that the commitment complex factor Mud2p may function in cotranscriptional cross-intron bridging as well as in the cotranscriptional recruitment of U1 snRNP to the branchpoint of introns with weakened $5^{\prime}$ splice sites. $\Delta d s t 1$ shows similar phenotypes to $\Delta$ mud2, whereas $\Delta$ paf1 displays a different cotranscriptional splicing phenotype. The results indicate that this genetic strategy accesses the interface between transcription and splicing in yeast.

One possible reason for the observed "protection from RZ cleavage" is that the intron is removed by splicing before cleavage. Indeed, splicing occurs cotranscriptionally, as shown in Figure 2. The intron MS2 and split MS2 curves are almost exactly reversed (Fig. 2B,C), and lead to similar conclusions: Significant exon ligation and intron removal have occurred when transcription is $\sim 1 \mathrm{~kb}$ past the intron. Loss of the intron MS2 signal reached background levels by $\sim 1.5-2 \mathrm{~kb}$ past the intron (Fig. 2B, blue), suggesting that most, if not all, nascent introns are cotranscriptionally removed. However, we suspect that some HZ18 transcripts are post-transcriptionally spliced. This would consolidate the observed wild-type cotranscriptional cleavage activity (Fig. 1C) with the small splitMS2 RZ/mutRZ ChIP differences (Fig. 3B) and the observed liquid $\beta$-gal cleavage activity of $\sim 55 \%$.

Nonetheless, we favor the notion that an even earlier commitment to spliceosome assembly rather than splicing itself is responsible for the protection from the effects of intronic RZ cleavage (Fig. 1C). A comparison of RZ cleavage (Fig. 1B) with cotranscriptional splicing and snRNP recruitment (Fig. 2D) suggests that the wild-type intron is already protected prior to peak $\mathrm{U} 2$ values and significant splicing. Consistent with this idea, a deletion of the commitment complex protein Mud2p sensitizes an intron to RZ cleavage (Fig. 3). Since Mud2p is important for the in vivo recruitment of U1 snRNP to the branchpoint region of an intron with a compromised 5' splice site (Fig. 4), we propose that Mud2p contributes to a cotranscriptional U1 snRNP cross-intron bridging complex. This complex contacts sequences both $5^{\prime}$ (the $5^{\prime}$ SS) and $3^{\prime}$ (the branchpoint) of the ribozyme and provides resistance to RZ cleavage in between. Once a strong bridge has been made, covalent contiguity between the two sides of the intron is unnecessary for successful splicing. Alternatively, Mud2p is necessary for the inhibition of RZ activity by the spliceosome. However, we favor the bridging model because both strains show $\sim 99.9 \%$ intron cleavage by RT-PCR (Supplementary Fig. 2). The lack of a $\Delta$ mud2 effect on U1 recruitment or on splicing of the wild-type HZ18 gene (Fig. 4B) presumably reflects the presence of residual (less stable) bridging contacts, which are sufficient for commitment in the absence of RZ cleavage. Cross-intron bridging by yeast U1 snRNP may constitute intron definition and be the in vivo equivalent of commitment complex formation in vitro (Seraphin and Rosbash 1989; Abovich and Rosbash 1997). In contrast, Proudfoot and colleagues (Dye et al. 2006) prefer a PolII exon-tethering model to explain similar splicing-protection from nascent RZ cleavage in a mammalian system; these experiments were published while this manuscript was in preparation.

Interestingly, the RZ/mutRZ plate and ChIP phenotypes of the transcription elongation factor TFIIS deletion strain were similar to those of the $\Delta$ mud2 strain (cf. Figs. $3 \mathrm{~A}, \mathrm{C}$ and $5 \mathrm{~A}, \mathrm{~B})$, suggesting that two very different 
biochemical pathways can lead to comparable defects in cotranscriptional splicing. However, there are two important differences between the two strains. The first is the lack of a RZ effect on the U1 recruitment patterns in the $\Delta d s t 1$ background. This may indicate that the $\Delta d s t 1$ effect is later in spliceosome assembly than the $\Delta$ mud2 effect; i.e., some post-commitment complex addition or rearrangement step is affected by the absence of TFIIS. Alternatively, the $\mathrm{U} 1$ recruitment assay is unable to detect a qualitative effect of $\Delta d s t 1$ on nascent commitment complex formation. The second difference between $\Delta$ mud2 and $\Delta d s t 1$ is the apparent lack of a $\Delta d s t 1$ effect on the mutRZ reporter. This is in contrast to $\Delta$ mud2; it has an effect on both reporters, although it is more severe on RZ than on mutRZ. This difference between $\Delta$ mud2 and $\Delta d s t 1$ may just reflect a stronger quantitative effect of $\Delta$ mud2 on splicing and the fact that the HZ18, mutRZ, and RZ reporters are a series of introns with decreasing efficiencies. $\Delta$ mud2 can then (negatively) affect both the mutRZ and RZ reporters but not HZ18, whereas the weaker $\Delta d s t 1$ can only impact the least efficient RZ intron.

It is perhaps more likely that the $\Delta d s t 1$ effects are qualitatively distinct from those of $\Delta$ mud2. This reflects the abundant evidence indicating that Mud2p is a splicing factor and that TFIIS is a PolII elongation factor (Abovich et al. 1994; Rain and Legrain 1997; Rutz and Seraphin 1999; Wind and Reines 2000). Indeed, plasmid overexpression of TFIIS led to increased exon skipping of a two intron yeast gene and was interpreted to be due to an increase in elongation rate (Howe et al. 2003), which has been shown to influence exon skipping in higher eukaryotes (Kadener et al. 2002; de la Mata et al. 2003). There are, however, reasons to suspect the elongation speed interpretation of this TFIIS splicing result. First, recent experiments directly measured transcriptional elongation and processivity of $\Delta d s t 1$ with no detectable effect; similar results were obtained with mutants in two members of the PAF1 complex (see below) (Mason and Struhl 2005). Second, there is no more than a small $\Delta d s t 1$ effect on PolII density (Supplementary Fig. 1C), which is insufficient to fully account for the splicing effects. Third, the lack of a detectable U1 snRNP recruitment phenotype suggests little or no $\Delta d s t 1$ elongation effect between the RZ sequence and the end of the intron (Fig. 5; Lacadie and Rosbash 2005). These considerations suggest that TFIIS-deficient PolII affects splicing, directly or indirectly. It is also possible that TFIIS-deficient PolII potentiates RZ cleavage in some splicing-independent manner, although an effect of TFIIS overexpression on exon skipping makes this possibility less likely (Howe et al. 2003).

An effect of polymerase or chromatin structure/modification on splicing is also made more likely by the phenotypes of the $\Delta$ paf1 strain, which were different from those of $\Delta d s t 1$ in two major ways: (1) Despite a marked plate phenotype, there was little or no RZ versus mutRZ effect, and (2) there was a substantial increase in the split MS2 ChIP signal without a RZ versus mutRZ difference (Fig. 6). The lack of an enhanced RZ effect also argues that altered transcription elongation cannot fully explain the $\Delta$ paf1 as well as the $\Delta d s t 1$ phenotypes. Moreover, the increase in split MS2 signal cannot be attributed to the small apparent PolII level increase, which might even be partially due to an 8WG16 antibody preference and a decrease in PolII ser-2 phosphorylation in the $\Delta$ paf1 strain (see Supplementary Fig. 1D and legend; Mueller et al. 2004). The apparent splicing increase might therefore be due to a true increase in cotranscriptional splicing. The still-lower RZ plate signal would then suggest that only a fraction of HZ18 splicing is cotranscriptional. Alternatively, the increased signal might reflect unmasking of an inherently low split MS2 signal, e.g., a $\Delta$ paf1altered chromatin or nascent RNP structure that makes the stem-loop more ChIP-accessible.

In any case, the different phenotypes of the two "elongation" mutants suggest that TFIIS and the PAF complex differentially affect the cotranscriptional splicing machinery. This conclusion is consistent with splicing-sensitive microarray analyses of $\Delta d s t 1$ and $\Delta p a f 1$, which indicate that they both affect splicing but in different ways. $\Delta d s t 1$ showed an accumulation of unspliced premRNAs relative to total transcripts, and the detailed phenotype clustered with other mutants like the PolII CTD truncation mutant $r p b \Delta 101$ and mutants of the CTD kinases, Kin28p and Burlp (Burckin et al. 2005). $\Delta$ paf1 also showed pre-mRNA accumulation but clustered with mutations in the export factors Sub2p, Yralp, and Mex67p (Burckin et al. 2005).

It is difficult to use genetics to demonstrate a direct influence of TFIIS and of the PAF complex on splicing. For example, Paflp influences 3' end formation as well as chromatin modification, which makes the splicing effects even more difficult to interpret mechanistically (Krogan et al. 2003; Ng et al. 2003; Wood et al. 2003; Penheiter et al. 2005). Nonetheless, the cotranscriptional assays presented here should continue to provide insights at the interface of splicing and transcription, and might also lend themselves to more biochemical approaches in the future, such as characterizing the composition of cotranscriptional splicing complexes in different genotypes.

\section{Materials and methods}

\section{Strains}

All strains used in this study are listed in Supplementary Table 1. We used standard methods for yeast manipulations (Guthrie and Fink 1991). TAP-tagged U1C strains in the $\Delta$ mud2 and $\Delta d s t 1$ backgrounds were made by PCR amplification of the tagged locus from the wild-type strain (see Table S1) and transformation of the PCR product into the knockout strains selecting for HIS3+ colonies. Strains deleted for the following proteins were used for the plate screen (note: except for Swilp deletion, which was a gift from Dr. Fred Winston, these strains were taken from the Open Biosystems knockout collection, and only those presented in the Results section have been verified by PCR): Hrb1p, Cus2p, Hprlp, Gbp2p, Ctk1p, Mlp1p, Mlp2p, Prp18p, Mud2p, Set2p, Isw1p, Mud13p, Spt4p, Rrp6p, Nam8p, Mud1p, Nab6p, Rsc2p, Cbp80p, Ioc2p, Ioc3p, Ioc4p, Snt309p, 
Psy2p, Cdc40p, Mig1p, YPL105Cp, Smy2p, Msl1p, Hs17p, Publp, Nam7p, Lrp1p, Skylp, Scp160p, Tom1p, Ssm4p, Tho2p, Mft1p, Thp2p, Tex1p, Sus1p, Sac3p, Thp1p, Yra2p, Nup84p, Airlp, Air2p, Apq12p, Zds1p, Gfd1p, Hmt1p, Mip6p, Dst1p, Syclp, Ref2p, Paflp, Cdc73p, Ctr9p, Rtf1p, Leo1p, Spt20p, Gcn5p, Bur2p, Cka2p, Chd1p, Isw2p, Itc1p, Rpl39p, Lsm12p, Lhplp, Brrlp, Swilp.

\section{Plasmid construction}

All reporters were constructed using QuikChange Site-Directed Mutatgenesis (Stratagene, no. 200,518) on pHZ18 (Teem and Rosbash 1983) or pHZ 55 (Lacadie and Rosbash 2005) with the primer pairs shown in Table S2.

\section{Chromatin immunoprecipitations}

Chromatin immunoprecipitations for TAP-tagged snRNPs and RNA polymerase with the 8 WG16 were performed as described previously (Abruzzi et al. 2004; Lacadie and Rosbash 2005). Anti-HA ChIPs for HA-MS2 were performed essentially as described (Abruzzi et al. 2004) with the following exceptions: Following de-cross-linking, DNA from input and IP samples was purified using the QIAquick PCR Purification Kit (Qiagen). PCR analysis was performed on a Rotorgene 3000 PCR machine (Corbett Research) with the primer pairs shown in Table S2, and the gene positions graphed were the center of each amplicon. Differences in primer pair efficiencies were accounted for by forming standard curves from serial dilutions of appropriate genomic DNA preparations during each real-time run. All samples in a single PCR run were assayed in triplicate. All data represent the average of at least two independent experiments, with the error bars displaying the average deviation.

\section{$\beta$-Galactosidase activity assays}

Liquid $\beta$-galactosidase assays were performed as previously described (Jacquier et al. 1985) with the following changes: Wildtype, $\Delta$ mud2, and $\Delta d s t 1$ strains were grown overnight in $2 \%$ raffinose and induced for $2 \mathrm{~h}$ with $2 \%$ galactose. Plate $\beta$-galactosidase assays were performed as follows: Yeast were struck to uracil dropout plates containing $0.1 \mathrm{~g} / \mathrm{L}$ of the $\beta$-galacotsidase substrate X-gal (5-Bromo-4-chloro-3-indolyl $\beta$-D-galactopyranoside; Sigma B4252-1G) and $2 \%$ galactose to induce reporter gene expression. Scans of the plates were made after $3 \mathrm{~d}$ of growth at $30^{\circ} \mathrm{C}$.

\section{$R T-P C R$}

Total yeast RNA was treated with RQ1 DNase according to the manufacturer's protocol (Promega M198A). One microgram of DNased RNA was reverse-transcribed with primer O324 (see Table S2) using Superscript II according to the manufacturer's protocol (Invitrogen 18064-014). cDNA was then quantified using real-time PCR with primers O325, O324, O321, and O322 (see Table S2). Data are presented as the signal observed across the cut site as measured by PCR with oligos O321 and O322 for the active RZ divided by the same signal for the mutant RZ and normalized for total introns as measured by PCR with oligos O325 and O324. This was to account for any differences between reverse transcription reactions.

\section{Acknowledgments}

We thank all the members of the Rosbash lab. Special thanks to Kate Abruzzi, Michael Green, and Melissa Moore for critical reading of the manuscript. Thanks also to Ken Dower for ideas on the splicing ChIPs, Julia Chekanova for her help in constructing the small deletion library, and David Bentley and Alberto Kornblihtt for useful discussions. Also special thanks to Kelly Miller for her help with the early phases of the plate screen. S.K. is a recipient of a long-term fellowship from the International Human Frontiers Science Program Organization. This work was supported in part by a grant to M.R. from the $\mathrm{NIH}$ (grant GM23549) and NIH Genetics Training Grant GM007122.

\section{References}

Abovich, N. and Rosbash, M. 1997. Cross-intron bridging interactions in the yeast commitment complex are conserved in mammals. Cell 89: 403-412.

Abovich, N., Liao, X.C., and Rosbash, M. 1994. The yeast MUD2 protein: An interaction with PRP11 defines a bridge between commitment complexes and U2 snRNP addition. Genes \& Dev. 8: 843-854.

Abruzzi, K.C., Lacadie, S., and Rosbash, M. 2004. Biochemical analysis of TREX complex recruitment to intronless and intron-containing yeast genes. EMBO J. 23: 2620-2631.

Ahn, S.H., Kim, M., and Buratowski, S. 2004. Phosphorylation of serine 2 within the RNA polymerase II C-terminal domain couples transcription and $3^{\prime}$ end processing. Mol. Cell 13: 67-76.

Bauren, G. and Wieslander, L. 1994. Splicing of balbiani ring 1 gene pre-mRNA occurs simultaneously with transcription. Cell 76: 183-192.

Bentley, D.L. 2005. Rules of engagement: Co-transcriptional recruitment of pre-mRNA processing factors. Curr. Opin. Cell Biol. 17: 251-256.

Berglund, J.A., Chua, K., Abovich, N., Reed, R., and Rosbash, M. 1997. The splicing factor BBP interacts specifically with the pre-mRNA branchpoint sequence UACUAAC. Cell 89: 781787.

Berglund, J.A., Abovich, N., and Rosbash, M. 1998. A cooperative interaction between U2AF65 and $\mathrm{mBBP} / \mathrm{SF} 1$ facilitates branchpoint region recognition. Genes \& Dev. 12: 858-867.

Beyer, A.L. and Osheim, Y.N. 1988. Splice site selection, rate of splicing, and alternative splicing on nascent transcripts. Genes \& Dev. 2: 754-765.

Burckin, T., Nagel, R., Mandel-Gutfreund, Y., Shiue, L., Clark, T.A., Chong, J.L., Chang, T.H., Squazzo, S., Hartzog, G., and Ares Jr., M. 2005. Exploring functional relationships between components of the gene expression machinery. Nat. Struct. Mol. Biol. 12: 175-182.

Cho, E.J., Takagi, T., Moore, C.R., and Buratowski, S. 1997. mRNA capping enzyme is recruited to the transcription complex by phosphorylation of the RNA polymerase II carboxy-terminal domain. Genes \& Dev. 11: 3319-3326.

Cho, E.J., Rodriguez, C.R., Takagi, T., and Buratowski, S. 1998. Allosteric interactions between capping enzyme subunits and the RNA polymerase II carboxy-terminal domain. Genes \& Dev. 12: 3482-3487.

de la Mata, M., Alonso, C.R., Kadener, S., Fededa, J.P., Blaustein, M., Pelisch, F., Cramer, P., Bentley, D., and Kornblihtt, A.R. 2003. A slow RNA polymerase II affects alternative splicing in vivo. Mol. Cell 12: 525-532.

$\mathrm{Du}, \mathrm{L}$. and Warren, S.L. 1997. A functional interaction between the carboxy-terminal domain of RNA polymerase II and premRNA splicing. J. Cell Biol. 136: 5-18.

Dye, M.J. and Proudfoot, N.J. 1999. Terminal exon definition occurs cotranscriptionally and promotes termination of 
RNA polymerase II. Mol. Cell 3: 371-378.

Dye, M.J., Gromak, N., and Proudfoot, N.J. 2006. Exon tethering in transcription by RNA polymerase II. Mol. Cell 21: 849859.

Fong, Y.W. and Zhou, Q. 2001. Stimulatory effect of splicing factors on transcriptional elongation. Nature 414: 929-933.

Furger, A., O'Sullivan, J.M., Binnie, A., Lee, B.A., and Proudfoot, N.J. 2002. Promoter proximal splice sites enhance transcription. Genes \& Dev. 16: 2792-2799.

Gornemann, J., Kotovic, K.M., Hujer, K., and Neugebauer, K.M. 2005. Cotranscriptional spliceosome assembly occurs in a stepwise fashion and requires the cap binding complex. Mol. Cell 19: 53-63.

Guthrie, C. and Fink, G.R. 1991. Guide to yeast genetics and molecular biology. Methods Enzymol. 194: 389-398.

Hirose, Y. and Manley, J.L. 1997. RNA polymerase II is an essential mRNA polyadenylation factor. Nature 395: 93-96.

Hirose, Y., Tacke, R., and Manley, J.L. 1999. Phosphorylated RNA polymerase II stimulates pre-mRNA splicing. Genes \& Dev. 13: 1234-1239.

Howe, K.J., Kane, C.M., and Ares Jr., M. 2003. Perturbation of transcription elongation influences the fidelity of internal exon inclusion in Saccharomyces cerevisiae. RNA 9: 9931006.

Huertas, P. and Aguilera, A. 2003. Cotranscriptionally formed DNA:RNA hybrids mediate transcription elongation impairment and transcription-associated recombination. Mol. Cell 12: $711-721$.

Jacquier, A., Rodriguez, J.R., and Rosbash, M. 1985. A quantitative analysis of the effects of $5^{\prime}$ junction and TACTAAC box mutants and mutant combinations on yeast mRNA splicing. Cell 43: 423-430.

Kadener, S., Fededa, J.P., Rosbash, M., and Kornblihtt, A.R. 2002. Regulation of alternative splicing by a transcriptional enhancer through RNA pol II elongation. Proc. Natl. Acad. Sci. 99: 8185-8190.

Kim, E., Du, L., Bregman, D.B., and Warren, S.L. 1997. Splicing factors associate with hyperphosphorylated RNA polymerase II in the absence of pre-mRNA. J. Cell Biol. 136: 19-28.

Kotovic, K.M., Lockshon, D., Boric, L., and Neugebauer, K.M. 2003. Cotranscriptional recruitment of the U1 snRNP to intron-containing genes in yeast. Mol. Cell. Biol. 23: 57685779.

Krogan, N.J., Dover, J., Wood, A., Schneider, J., Heidt, J., Boateng, M.A., Dean, K., Ryan, O.W., Golshani, A., Johnston, M., et al. 2003. The Pafl complex is required for histone H3 methylation by COMPASS and Dotlp: Linking transcriptional elongation to histone methylation. Mol. Cell 11: 721-729.

Lacadie, S.A. and Rosbash, M. 2005. Cotranscriptional spliceosome assembly dynamics and the role of U1 snRNA:5'ss base pairing in yeast. Mol. Cell 19: 65-75.

Lei, E.P. and Silver, P.A. 2002. Intron status and $3^{\prime}$-end formation control cotranscriptional export of mRNA. Genes \& Dev. 16: 2761-2766.

Lei, E.P., Krebber, H., and Silver, P.A. 2001. Messenger RNAs are recruited for nuclear export during transcription. Genes \& Dev. 15: 1771-1782.

LeMaire, M.F. and Thummel, C.S. 1990. Splicing precedes polyadenylation during Drosophila E74A transcription. Mol. Cell. Biol. 10: 6059-6063.

Libri, D., Graziani, N., Saguez, C., and Boulay, J. 2001. Multiple roles for the yeast SUB2/yUAP56 gene in splicing. Genes \& Dev. 15: 36-41.

Mason, P.B. and Struhl, K. 2005. Distinction and relationship between elongation rate and processivity of RNA polymer- ase II in vivo. Mol. Cell 17: 831-840.

McCracken, S., Fong, N., Rosonina, E., Yankulov, K., Brothers, G., Siderovski, D., Hessel, A., Foster, S., Shuman, S., and Bentley, D.L. 1997a. 5'-Capping enzymes are targeted to premRNA by binding to the phosphorylated carboxy-terminal domain of RNA polymerase II. Genes \& Dev. 11: 3306-3318.

McCracken, S., Fong, N., Yankulov, K., Ballantyne, S., Pan, G., Greenblatt, J., Patterson, S.D., Wickens, M., and Bentley, D.L. 1997b. The C-terminal domain of RNA polymerase II couples mRNA processing to transcription. Nature 385: 357-361.

Misteli, T. and Spector, D.L. 1999. RNA polymerase II targets pre-mRNA splicing factors to transcription sites in vivo. Mol. Cell 3: 697-705.

Misteli, T., Caceres, J.F., and Spector, D.L. 1997. The dynamics of a pre-mRNA splicing factor in living cells. Nature 387: 523-527.

Morris, D.P. and Greenleaf, A.L. 2000. The splicing factor, Prp40, binds the phosphorylated carboxyl-terminal domain of RNA polymerase II. J. Biol. Chem. 275: 39935-39943.

Mortillaro, M.J., Blencowe, B.J., Wei, X., Nakayasu, H., Du, L., Warren, S.L., Sharp, P.A., and Berezney, R. 1996. A hyperphosphorylated form of the large subunit of RNA polymerase II is associated with splicing complexes and the nuclear matrix. Proc. Nat1. Acad. Sci. 93: 8253-8257.

Mueller, C.L., Porter, S.E., Hoffman, M.G., and Jaehning, J.A. 2004. The Pafl complex has functions independent of actively transcribing RNA polymerase II. Mol. Cell 14: 447456.

Ng, H.H., Dole, S., and Struhl, K. 2003. The Rtf1 component of the Paf1 transcriptional elongation complex is required for ubiquitination of histone H2B. J. Biol. Chem. 278: 3362533628.

Osheim, Y.N., Miller Jr., O.L., and Beyer, A.L. 1985. RNP particles at splice junction sequences on Drosophila chorion transcripts. Cell 43: 143-151.

Penheiter, K.L., Washburn, T.M., Porter, S.E., Hoffman, M.G., and Jaehning, J.A. 2005. A posttranscriptional role for the yeast Paf1-RNA polymerase II complex is revealed by identification of primary targets. Mol. Cell 20: 213-223.

Rain, J.-C. and Legrain, P. 1997. In vivo commitment to splicing in yeast involves the nucleotide upstream from the branch site conserved sequence and the Mud2 protein. EMBO J. 16: $1759-1771$

Rodriguez, C.R., Cho, E.J., Keogh, M.C., Moore, C.L., Greenleaf, A.L., and Buratowski, S. 2000. Kin28, the TFIIH-associated carboxy-terminal domain kinase, facilitates the recruitment of mRNA processing machinery to RNA polymerase II. Mol. Cell. Biol. 20: 104-112.

Rondon, A.G., Gallardo, M., Garcia-Rubio, M., and Aguilera, A. 2004. Molecular evidence indicating that the yeast PAF complex is required for transcription elongation. EMBO Rep. 5: 47-53.

Rosonina, E. and Blencowe, B.J. 2002. Gene expression: The close coupling of transcription and splicing. Curr. Biol. 12: R319-R321.

Rutz, B. and Seraphin, B. 1999. Transient interaction of BBP/ ScSF1 and Mud2 with the splicing machinery affects the kinetics of spliceosome assembly. RNA 5: 1-13.

Samarsky, D.A., Ferbeyre, G., Bertrand, E., Singer, R.H., Cedergren, R., and Fournier, M.J. 1999. A small nucleolar RNA:ribozyme hybrid cleaves a nucleolar RNA target in vivo with near-perfect efficiency. Proc. Natl. Acad. Sci. 96: 6609-6614.

Seraphin, B. and Rosbash, M. 1989. Identification of functional U1 snRNA-pre-mRNA complexes committed to spliceosome assembly and splicing. Cell 59: 349-358. 
Lacadie et al.

Spector, D.L. 1993. Nuclear organization of pre-mRNA processing. Curr. Opin. Cell Biol. 5: 442-447.

Strasser, K. and Hurt, E. 2001. Splicing factor Sub2p is required for nuclear mRNA export through its interaction with Yralp. Nature 413: 648-652.

Strasser, K., Masuda, S., Mason, P., Pfannstiel, J., Oppizzi, M., Rodriguez-Navarro, S., Rondon, A.G., Aguilera, A., Struhl, K., Reed, R., et al. 2002. TREX is a conserved complex coupling transcription with messenger RNA export. Nature 417: 304-308.

Teem, J.L. and Rosbash, M. 1983. Expression of a $\beta$-galactosidase gene containing the ribosomal protein 51 intron is sensitive to the rna2 mutation of yeast. Proc. Natl. Acad. Sci. 80: 4403-4407.

Vincent, M., Lauriault, P., Dubois, M.F., Lavoie, S., Bensaude, O., and Chabot, B. 1996. The nuclear matrix protein p255 is a highly phosphorylated form of RNA polymerase II largest subunit which associates with spliceosomes. Nucleic Acids Res. 24: 4649-4652.

West, S., Gromak, N., and Proudfoot, N.J. 2004. Human $5^{\prime} \rightarrow 3^{\prime}$ exonuclease Xrn2 promotes transcription termination at cotranscriptional cleavage sites. Nature 432: 522-525.

Wetterberg, I., Zhao, J., Masich, S., Wieslander, L., and Skoglund, U. 2001. In situ transcription and splicing in the Balbiani ring 3 gene. EMBO J. 20: 2564-2574.

Wind, M. and Reines, D. 2000. Transcription elongation factor SII. Bioessays 22: 327-336.

Winzeler, E.A., Shoemaker, D.D., Astromoff, A., Liang, H., Anderson, K., Andre, B., Bangham, R., Benito, R., Boeke, J.D., Bussey, H., et al. 1999. Functional characterization of the $S$. cerevisiae genome by gene deletion and parallel analysis. Science 285: 901-906.

Wood, A., Schneider, J., Dover, J., Johnston, M., and Shilatifard, A. 2003. The Pafl complex is essential for histone monoubiquitination by the Rad6-Brel complex, which signals for histone methylation by COMPASS and Dotlp. I. Biol. Chem. 278: 34739-34742.

Wuarin, J. and Schibler, U. 1994. Physical isolation of nascent RNA chains transcribed by RNA polymerase II: Evidence for cotranscriptional splicing. Mol. Cell. Biol. 14: 7219-7225.

Yuryev, A., Patturajan, M., Litingtung, Y., Joshi, R.V., Gentile, C., Gebara, M., and Corden, J.L. 1996. The C-terminal domain of the largest subunit of RNA polymerase II interacts with a novel set of serine/arginine-rich proteins. Proc. Natl. Acad. Sci. 93: 6975-6980. 


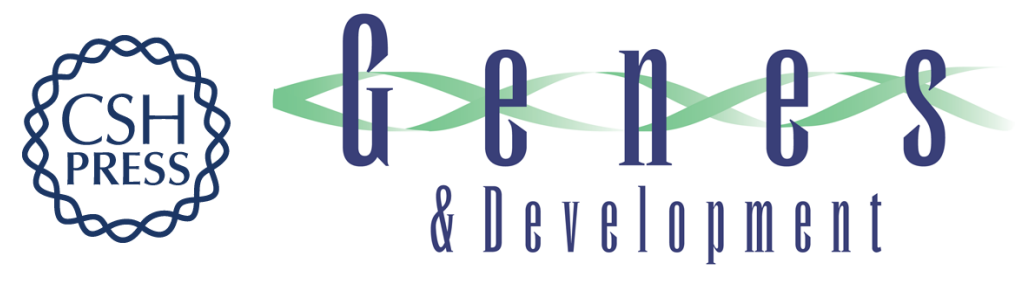

\section{In vivo commitment to yeast cotranscriptional splicing is sensitive to transcription elongation mutants}

Scott A. Lacadie, Daniel F. Tardiff, Sebastian Kadener, et al.

Genes Dev. 2006, 20:

Access the most recent version at doi:10.1101/gad.1434706

Supplemental http://genesdev.cshlp.org/content/suppl/2006/07/14/20.15.2055.DC1
Material

References This article cites 64 articles, 31 of which can be accessed free at: http://genesdev.cshlp.org/content/20/15/2055.full.html\#ref-list-1

License

Email Alerting

Receive free email alerts when new articles cite this article - sign up in the box at the top Service right corner of the article or click here.

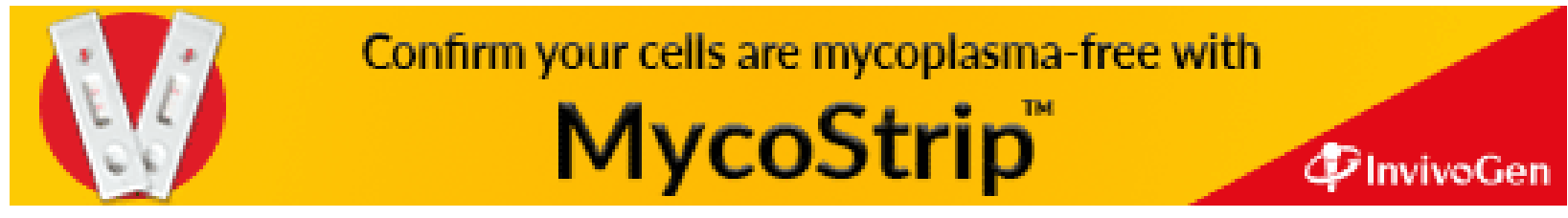

